(6) OPEN ACCESS

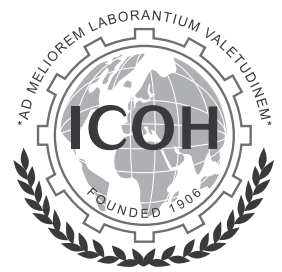

'Department of Occupational and Environmental Medicine Epidemiology and Hygiene, Italian Workers' Compensation Authority (INAIL), Monte Porzio Catone (Rome), Italy

${ }^{2} S$ chool of Public Health, University of Sydney, Sidney, New South Wales, Australia ${ }^{3}$ Faculty of Occupational Medicine, Royal College of Physicians of Ireland, Dublin, Ireland

${ }^{4}$ Section of Occupational Medicine, Department of Public Health, University of Naples Federico II, Naples, Italy ${ }^{5}$ Department of Public Health/ Occupational Health, University of Helsinki, Helsinki, Finland ${ }^{6}$ IARC Monographs Section, International Agency for Research on Cancer (IARC), Lyon, France

${ }^{7}$ International Commission on Occupational Health (ICOH), Milan, Italy

\section{Correspondence to}

Dr Sergio lavicoli, Occupational Medicine Department, Italian Workers' Compensation Authority (INAIL), Rome I-00040, Italy; s.iavicoli@inail.it

Received 23 October 2018 Revised 4 March 2019 Accepted 21 April 2019

Check for updates

(C) Author(s) (or their employer(s)) 2019. Re-use permitted under CC BY-NC. No commercial re-use. See rights and permissions. Published by BMJ.

To cite: lavicoli $S$, Driscoll TR, Hogan M, et al. Occup Environ Med 2019:76:360-362

\title{
New avenues for prevention of occupational cancer: a global policy perspective
}

\author{
Sergio lavicoli, ${ }^{1}$ Tim R Driscoll, ${ }^{2}$ Martin Hogan, ${ }^{3}$ Ivo lavicoli, ${ }^{4}$ Jorma Harri Rantanen, ${ }^{5}$ \\ Kurt Straif, ${ }^{6}$ Jukka Takala ${ }^{7}$
}

Recent estimates demonstrated that occupational cancer accounted for $27 \%$ of the 2.4 million deaths due to work-related diseases. ${ }^{1-3}$ In numerical terms, this estimate means that the number of deaths attributable to occupational cancer annually increased from 666000 deaths in 2011 to 742000 deaths in $2015 .^{23}$ This increase could be explained by different variables such as the evidence on new carcinogens, the methods of estimation, changes in the industry distribution of workers and the growing and ageing of the population. The International Labour Organization (ILO) released global data showing this increase in the number of fatal work-related cancers that occur every year, ${ }^{3}{ }^{4}$ whereas, in the European Union (EU) alone, occupational cancer was responsible for 102500 deaths in 2011 and 106300 in $2015 .^{2-5}$

Considering these data, it is clear that occupational cancer now represents the primary cause for work-related deaths globally and in many regions of the world, and the numbers continue to grow. In spite of efforts for prevention and control by several international organisations, institutions and authorities, the level of occupational cancer mortality and morbidity has remained high. Part of the reason for this is that current burden reflects the effect of past exposures and so provides little insight into the effectiveness of recent (in the last two decades) control measures. However, burden estimates do indicate that systems in place in past decades do not appear to have been effective enough, and there is good reason to suspect many of these systems, or systems similar to them, remain in place in many regions. For this reason, occupational cancer prevention was a key theme of the 32nd International Congress on Occupational Health (ICOH) held in Dublin from 29 April to 4 May 2018. ${ }^{6}$ The Dublin Statement on Occupational Health 'New Avenues for Prevention of Occupational Cancer and Other Severe Occupational Health Hazards', adopted unanimously by the ICOH 2018 Congress, summarises the needs and presents the main elements of the fight against occupational cancer in the years to come.

In this regard, it should be noted that one of the most interesting insights that came out during the ICOH Congress concerned the importance of the implementation of policy on the prevention of occupational cancer. To achieve this ambitious objective, it is necessary to invest significant human and economic resources defining, implementing and promoting a global strategy and action plan, which should be based on integrated interventions and tools intervening on multiple operational levels and ranging from research to prevention and control (online supplementary table 1).

Obviously, we are not at a starting point, and important progress has been made (see, eg, the UN 2030 Agenda for Sustainable Development or the 70th World Health Assembly Resolution No. 70.32 of 2017 on cancer prevention and control in the context of an integrated approach) ${ }^{7}$; nevertheless, there is still much work to be done. For example, in the regulatory context, the carcinogenic hazard identification and risk assessment of a substance, agent and/or working process are important prerequisites for risk management. Indeed, identifying occupational carcinogens is an essential research effort since these data represent the basis on which to define prevention and surveillance measure priorities. Furthermore, a strengthening in the evaluation (and definition) of occupational carcinogens is needed to obtain more appropriate and realistic estimates of the global burden of occupational cancer (online supplementary table 1). However, to achieve this target, it is also essential to have reliable information on key exposure characteristics (eg, number of exposed workers; environmental and biological monitoring data). Different sources of information (national registers or exposure measurement databases-see online supplementary table 1) are available at both international and national level. ${ }^{89}$ Moreover, in this context, it should be noted that there are also international and national exposure information systems, which are based on expert estimations of numbers of exposed workers and their level of exposure to occupational carcinogens. ${ }^{8}$

Exposure registers, databases and expert estimations are valuable tools to characterise the workers' exposure to occupational carcinogens. Nevertheless, their use in the broader context of establishing global policies to tackle and prevent occupational cancers is still limited for several reasons (online supplementary table 1). First of all, these instruments do not cover all occupational carcinogens and regions (eg, the ExpoSYN is an exposure measurement database developed for the SYNERGY research project and focused on five lung carcinogens and was based on data from Europe and Canada). ${ }^{9}$ Furthermore, they should be made more informative through refinement (eg, data by gender and exposure levels), expansion (CAREX is based on the 15 EU countries in 1990) and regular updating (eg, the CAREX estimates of exposure prevalence and numbers of exposed workers refer to the period 1990-1993, and updates were carried out only for Finland, Italy and Spain). ${ }^{10}$ In this 
regard, another critical issue is the lack of harmonisation of the different registers, databases and expert estimates. Therefore, there is a clear need to globally harmonise the existing sources of information on exposure in order to achieve a more accurate and reliable basis for the estimation of global burden of occupational cancer. It should be pointed out that the assessment of exposure remains the single best instrument for identification and quantification of problems benchmarking and documentation of progress.

With regard to the prevention and protection area of interest, there are several primary and/or secondary prevention measures that can be used in workplaces to ensure the health protection of workers exposed to carcinogens. According to the ILO convention C-139 on occupational cancer, 'carcinogenic substances or agents must be replaced by non-carcinogenic substances or agents or by less harmful substances or agents'. Such an intervention strategy has been adopted for asbestos, which currently has been banned in 55 countries. ${ }^{11}$ However, the programmes and policies for the complete and global elimination of a carcinogen require important resources and global implementation. In fact, asbestos is still widely used today (approximately 2030000 tons of this substance are consumed annually). ${ }^{11}$ Furthermore, it is not always technically possible to completely eliminate a carcinogenic substance or agent from the workplace. In this regard, in years to come, a fundamental contribution to the elimination of the use of occupational carcinogens could be provided by technological innovation which, through continuous scientific progress and identification of innovative working processes, could lead to the substitution of these harmful substances.

Meanwhile, the application of technical, organisational or procedural preventive measures to reduce workers' exposure to occupational carcinogens is even more relevant (online supplementary table 1). Therefore, the adoption (or the updating) of specific occupational exposure limits (OELs) for these substances has become increasingly important. In this regard, very recently (on 5 April 2018), the European Commission proposed to further amend the Carcinogens and Mutagens Directive 2004/37/ EC, establishing new OEL values for five cancer-causing chemicals (online supplementary table 1). Previously (May 2016 and January 2017), similar initiatives had been undertaken to protect workers from occupational cancers related to exposure to another 21 substances.

Another area of intervention, which offers ample room for improvement in terms of prevention activities, is linked to the development and dissemination of specific training and information campaigns (eg, 'No time to lose' and 'The Roadmap on Carcinogens') to raise awareness of occupational cancer risks. The Roadmap on Carcinogens was started by the Conference organised by the EU Presidency of The Netherlands in 2016 followed by the Austrian Presidency at the Vienna Conference by EU governments, workers and employers in September 2018, and the next step will be the Finnish EU Presidency in 2019. ICOH has had a key role from the very beginning of this process. ${ }^{12}$ Indeed, the currently available data show that awareness is still not sufficiently developed, and this is a critical issue ${ }^{9}$ since a greater understanding of health risks related to occupational carcinogen exposure would ensure an improvement in compliance with the several preventive and protective measures and/or with good working practices.

With regard to secondary prevention measures and control activities, a global policy aimed at effectively addressing the burden of occupational cancer should include not only interventions to limit or avoid future exposures but also actions to safeguard and protect the health of workers who have previously been exposed to occupational carcinogens. The follow-up of carcinogen-exposed workers is a very important topic, especially considering that many cancers have a long latency period after the initial exposure. Moreover, with increasing life expectancy, continued surveillance and screening (for some cancers) extending beyond retirement become even more important. For example, the Consensus Report 'Asbestos, asbestosis and cancer. The Helsinki Criteria for Diagnosis and Attribution 2014' suggested that the follow-up of highly asbestos-exposed workers should be continued at least for up to 30 years after the cessation of exposure. ${ }^{13}$ In this context, the use of appropriate organised screening programmes (such as low-dose CT for formerly asbestos-exposed workers) would increase the chances of an early diagnosis of occupational cancer, thus potentially reducing mortality and increasing the chances of surviving disease (online supplementary table 1). Moreover, follow-up, using specific structured questionnaires and/or checklists in order to investigate and identify past or current exposures, is necessary from a compensation point of view.

In conclusion, the Global Policy Forum 'Prevention of Occupational Cancer: Global Policies and Strategies' highlighted the need to define a global policy on this topic as an urgent matter. Indeed, despite the important progress made in recent years, further efforts are required at all levels. Information provided in this article can help in determining which interventions and actions are most urgent and therefore support the development of a priority action strategy to control and reduce occupational cancer as effectively as possible.

Contributors SI and II contributedto the development of the ideas explored in the manuscript and wrote the firstdraft of the manuscript. TD, MH, JR and KS contributedto the development of the ideas explored in the manuscript and reviewed thedraft manuscript. JT supervised the global policy forum entitled "Prevention ofOccupational Cancer: Global Policies and Strategies", contributed to the developmentof the ideas explored in the manuscript and reviewed the draft manuscript. Allauthors reviewed and approved the final version of the manuscript forpublication.

Funding The authors have not declared a specific grant for this research from any funding agency in the public, commercial or not-for-profit sectors.

Competing interests None declared.

Patient consent for publication Not required.

Provenance and peer review Not commissioned; internally peer reviewed.

Open access This is an open access article distributed in accordance with the Creative Commons Attribution Non Commercial (CC BY-NC 4.0) license, which permits others to distribute, remix, adapt, build upon this work non-commercially, and license their derivative works on different terms, provided the original work is properly cited, appropriate credit is given, any changes made indicated, and the use is non-commercial. See: http://creativecommons.org/licenses/by-nc/4.0/.

\section{REFERENCES}

1 Takala J, Hämäläinen P, Saarela KL, et al. Global estimates of the burden of injury and illness at work in 2012. J Occup Environ Hyg 2014;11:326-37.

2 Takala J, cancer Eoccupational/nd Health 2015;53:307-9.

3 Nenonen N, Hämäläinen $\mathrm{P}$, Takala J, et al; Global estimates of occupational accidents and fatal work-related diseases in 2014. Singapore: Workplace Safety \& Health Institute. https://goo.gl/aTsZcv (accessed 20 Sept 2018).

4 ILO. Director General Guy Ryder Opening Address at XXI World Congress on Safety and Health. Singapore XXI World Congress on Occupational Safety and Health www.ilo.org/global/about-the-ilo/how-the-ilo-works/ilo-director-general/ statements-and-speeches/WCMS_639102/lang-en/index.htm (accessed 20 Sept 2018).

5 Hämäläinen P, Takala J, Tan BK. Global estimates of occupational accidents and fatal work-related diseases in 2017. Singapore: Workplace Safety and Health Institute. https://goo.gl/hTZaW5 (accessed 20 Sept 2018).

6 Durand-Moreau Q, Descatha A, Paris C, et al. Qu retenir du $32^{e}$ Congrès de la Commission internationaled e la santé au travail (CIST-ICOH)? (Hot topics in ICOH 32nd Congress). Archives des Maladies Professionnelles et de l'Environnement 2018 https://doi.org/ (accessed 20 Sept 2018). 
7 International Commission on Occupational Health (ICOH). New Avenues for Prevention of Occupational Cancer and Other Severe Occupational Health Hazards. 32nd International Congress on Occupational Health: Dublin Statement on Occupational Health. http://www.icohweb.org/site/multimedia/news/pdf/Dublin\% 20Statement\%20on\%200H.pdf (accessed 10 Sept 2018).

8 European Agency for Safety and Health at Work. Exposure to carcinogens and workrelated cancer: A review of assessment methods. European Risk Observatory Report, European Agency for Safety and Health at Work. Luxembourg: Publications Office of the European Union, 2014.

9 Hovanec J, Siemiatycki J, Conway DI, et al. Lung cancer and socioeconomic status in a pooled analysis of case-control studies. PLoS One 2018;13:e0192999.
10 Kauppinen T, Toikkanen J, Pedersen D, et al. Occupational exposure to carcinogens in the European Union. Occup Environ Med 2000;57:10-18.

11 Furuya S, Chimed-Ochir O, Takahashi K, et al. Global Asbestos Disaster. Int J Environ Res Public Health 2018:15:1000.

12 Takala J. Carcinogens at Work: A look into the future. Vienna: Austrian EU Presidency, 2018. ICOH Presentation and Roadmap website. https://www.slideshare. net/jstakala, https://roadmaponcarcinogens.eu/news/ 24-25. (Accessed 03 Oct 2018).

13 Wolff H, Vehmas T, Oksa P, et al. Asbestos, asbestosis, and cancer, the Helsinki criteria for diagnosis and attribution 2014: recommendations. Scand J Work Environ Health 2015;41:5-15. 